\title{
Stromal expression of matrix metalloproteinase 2 in cancer-associated fibroblasts is strongly related to human epidermal growth factor receptor 2 status in invasive breast carcinoma
}

\author{
XAVIER CATTEAU ${ }^{1-3}$, PHILIPPE SIMON ${ }^{2,4}$ and JEAN-CHRISTOPHE NOËL ${ }^{2,5}$ \\ ${ }^{1}$ Institute of Pathology and Genetics, B-6041 Gosselies; ${ }^{2}$ Faculty of Medicine, Université Libre de Bruxelles, \\ B-1070 Brussels; ${ }^{3}$ Department of Pathology, Tivoli University Hospital-Université Libre de Bruxelles, \\ B-7100 La Louvière; ${ }^{4}$ Gynaecology Unit and ${ }^{5}$ Gynaecopathology Unit, Department of Pathology, \\ Erasme University Hospital-Université Libre de Bruxelles, B-1070 Brussels, Belgium
}

Received August 13, 2015; Accepted November 3, 2015

DOI: $10.3892 / \mathrm{mco} .2015 .721$

\begin{abstract}
The peritumoral stroma and cancer-associated fibroblasts (CAFs) have been suggested to play an important role in breast tumorigenesis. The specific immunohistochemical characteristics of the stromal component according to the breast carcinoma subtype surrogates of molecular classes is poorly understood. In the present study, immunohistochemical staining was used to evaluate the expression of matrix metalloproteinase 2 (MMP2), which is one of the most important proteins considered to facilitate tumor invasion, in a series of invasive breast carcinomas according to subtype: Luminal A, luminal B, luminal-HER2, HER2-enriched and triple-negative. A significant increase in MMP2 expression was demonstrated in tumors known to exhibit a more aggressive metastatic behavior, such as luminal HER2 (37\%), HER2-enriched (30\%) and triple-negative tumors (17\%), compared with the luminal A $(6 \%)$ or luminal B $(13 \%)$ subtypes. Our data indicated that the CAFs associated with different breast subtypes exhibit different specific properties to facilitate tumor invasion.
\end{abstract}

\section{Introduction}

Over several years, the majority of studies on breast carcinoma have focused only on the epithelial component; however, the tumor-associated stroma and particularly the cancer-associated

Correspondence to: Dr Xavier Catteau, Department of Pathology, Tivoli University Hospital-Université Libre de Bruxelles, 34 Max Buset Avenue, B-7100 La Louvière, Belgium

E-mail: xavier.catteau06@gmail.com

Key words: breast carcinoma, cancer-associated fibroblasts, myofibroblasts, peritumoral stroma, matrix metalloproteinase 2, luminal, human epidermal growth factor receptor-2 fibroblasts (CAFs) have been found to play a crucial role in cancer pathogenesis $(1,2)$.

We previously demonstrated that the majority of these CAFs were smooth muscle actin (SMA)-positive, with a myofibroblastic-like phenotype, and that the presence of these peritumoral myofibroblasts (PMYs) is crucial for in situ and invasive breast carcinoma of no special type (NST), as well in metastatic disease $(3,4)$. The origin of PMYs remains debatable, but we previously demonstrated that the resident CD34-positive breast fibroblasts are able to acquire SMA myofibroblastic characteristics under the control of the transforming growth factor $\beta-1$ pathway (3). It was suggested that these PMYs promote tumor invasion, growth and angiogenesis through paracrine factors and/or direct cell-cell crosstalk (5). Therefore, it was suggested that CAFs/PMYs potentially secrete various proteins, particularly matrix metalloproteinase 2 (MMP2), to facilitate tumor invasion $(6,7)$. To elucidate this issue, we immunohistochemically analyzed the expression of MMP2 in normal breast stromal fibroblasts and in $\mathrm{CAFs} / \mathrm{PMYs}$ present in invasive breast carcinoma of NST, according to clinicopathological variables. Our data were reviewed according to the highlights of the recent literature.

\section{Materials and methods}

Specimens. Formalin-fixed, paraffin-embedded postsurgical specimens from human breast carcinomas were retrieved from the archives of the Department of Pathology, Erasme University Hospital-Université Libre de Bruxelles (Brussels, Belgium). A total of 155 patients with invasive breast carcinoma of NST, who underwent surgery between 1997 and 2004, were randomly selected. A total of 20 specimens of normal breast tissue obtained from women who underwent resection for plastic surgery were also included in the study as controls. This study was approved by the Ethics Committee of Erasme University Hospital (reference no. P2014/418). The pathological stage and grade were 
defined according to the 2014 criteria of the World Heath Organization (8). A clinically positive test for estrogen and progesterone nuclear receptors (ER and $\mathrm{PR}$, respectively) was defined as nuclear staining in $\geq 1 \%$ of the tumor cells, as previously described (9). Human epidermal growth factor receptor 2 (HER2) immunoreactivity was performed using the Oracle HER2 test (clone CB11; Leica Microsystems $\mathrm{GmbH}$, Wetzlar, Germany) according to the manufacturer's instructions, and scoring was performed according to the recommendations of the American Society of Clinical Oncology (10). All HER2 scores of 2+ and 3+ were analyzed using the fluorescent in situ hybridization (FISH) PathVysion HER2 DNA test (Abbott Laboratories, Abbott Park, IL, USA) according to the manufacturer's instructions. Signal ratios (HER2/chromosome 17 centromere) of $\geq 2$ were classified as amplified. In the present study, only $2+$ and $3+$ tumors with HER2 FISH amplification were considered as positive. A subtype immunohistochemical classification, as previously described with certain modifications (11), was adopted to characterize the tumors as follows: Luminal A (either one or both ER and PR present, HER2-negative and Ki-67 $\leq 14 \%$ ); luminal B (one or both ER and PR present, HER2-negative and Ki-67 >14\%); luminal-HER2 (one or both ER and PR present, HER2-positive, irrespective of the Ki-67 index); HER2-positive (ER and PR absent, HER2-positive, irrespective of the Ki-67 index); and triple-negative (ER and PR absent and HER2-negative).

Immunostaining for MMP2 (clone 17B11, dilution 1:30; Leica Microsystems $\mathrm{GmbH}$ ) was performed using a fully automated immunohistochemical system (Autostainer Link A48; Dako, Glostrup, Denmark).

A two-grade system was used to score the stromal expression of MMP2, which was classified as positive or negative according to a cut-off of $10 \%$.

Statistical analysis. The Chi-square or Fisher's exact tests were used to statistically compare the clinicopathological variables described in the Table I. P $<0.05$ was considered to indicate a statistically significant difference.

\section{Results}

Stromal MMP2 expression. No MMP2 expression was observed in the stroma surrounding normal breast acini or ductal units (Fig. 1). By contrast, MMP2 expression was present in the peritumoral stroma in 24 of the 155 cases (15\%) of invasive breast carcinoma (Fig. 1). According to the different clinical parameters, there was no correlation between MMP2 stromal expression and patient age, histological grade, lymph node involvement, ER/PR positivity, or Ki-67 index. Conversely, MMP2 stromal expression was statistically significantly different in tumors sized $\leq 20 \mathrm{~mm}(21 \%$ positivity) compared with tumors $>20 \mathrm{~mm}$ ( $8 \%$ positivity) $(\mathrm{P}=0.02)$. In addition, stromal expression in HER2-positive carcinomas was more frequent compared with that in in HER2-negative tumors (35 vs. 12\%, respectively; $\mathrm{P}=0.002$ ). Finally, according to the subtype immunohistochemical classification surrogates of molecular classes, MMP2 stromal expression appeared more frequently by decreasing order in luminal-HER2 (37\%), HER2-enriched (30\%), triple-negative
Table I. Clinicopathological chracateristics of the 155 patients included in the study.

\begin{tabular}{|c|c|}
\hline Characteristics & $\begin{array}{l}\text { Total cases, no. }(\%) \\
\qquad(\mathrm{n}=155)\end{array}$ \\
\hline \multicolumn{2}{|l|}{ Age (years) } \\
\hline$<50$ & $46(30)$ \\
\hline$\geq 50$ & $109(70)$ \\
\hline \multicolumn{2}{|l|}{ Tumor size (mm) } \\
\hline$\leq 20$ & $90(58)$ \\
\hline$>20$ & $65(42)$ \\
\hline \multicolumn{2}{|l|}{ Lymph node status } \\
\hline Negative & $87(56)$ \\
\hline Positive & $68(44)$ \\
\hline \multicolumn{2}{|l|}{ Histological grade } \\
\hline 1 & 27 (17) \\
\hline 2 & $63(41)$ \\
\hline 3 & $65(42)$ \\
\hline \multicolumn{2}{|l|}{ ER status } \\
\hline Negative & $21(14)$ \\
\hline Positive & $134(86)$ \\
\hline \multicolumn{2}{|l|}{ PR status } \\
\hline Negative & $37(24)$ \\
\hline Positive & $118(76)$ \\
\hline \multicolumn{2}{|l|}{ HER2 status } \\
\hline Negative & $126(81)$ \\
\hline Positive & 29 (19) \\
\hline \multicolumn{2}{|l|}{ Ki-67 } \\
\hline$<15 \%$ & $35(23)$ \\
\hline$\geq 15 \%$ & $120(77)$ \\
\hline \multicolumn{2}{|c|}{ Molecular subtypes } \\
\hline Luminal A & $34(22)$ \\
\hline Luminal B & $86(55)$ \\
\hline Luminal-HER2 & $19(12)$ \\
\hline HER2-enriched & $10(7)$ \\
\hline Triple-negative & $6(4)$ \\
\hline
\end{tabular}

ER, estrogen receptor; PR, progesterone receptor; HER2, human epidermal growth factor receptor.

(17\%), luminal B (13\%) and luminal A $(6 \%)$ tumors $(\mathrm{P}=0.025)$ (Table II).

\section{Discussion}

Several recent studies support the hypothesis that, in invasive breast carcinoma, the gene expression profile of the epithelial component and, therefore, the immunohistochemical profile surrogates of molecular classes, represent biologically distinct diseases with different response to therapy and clinical outcome $(12,13)$. In addition to the epithelial cell autonomous processes, it has been hypothesized that the tumor microenvironment, and particularly CAFs, are able to promote tumor 
A

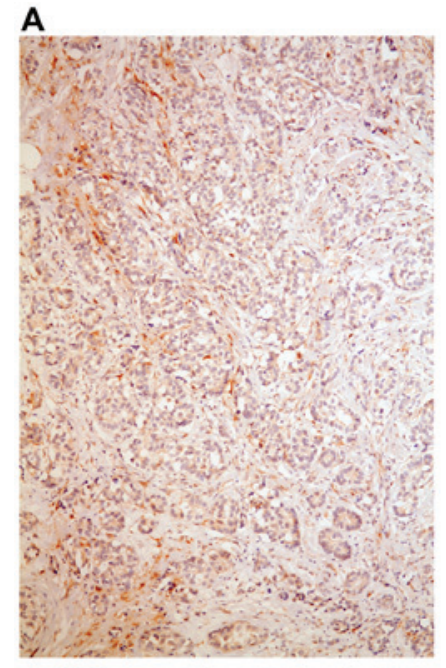

B

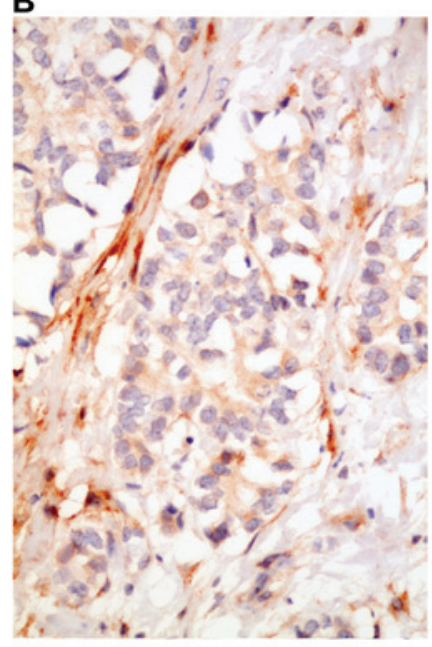

C

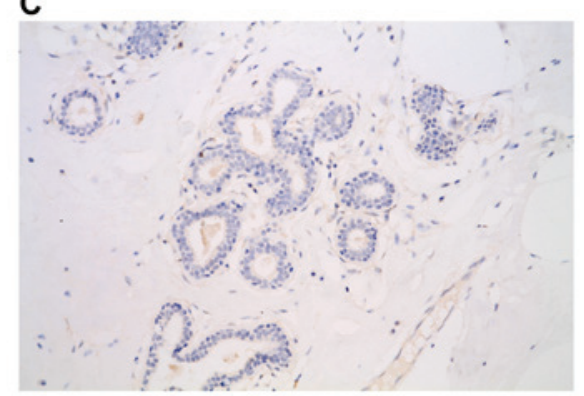

Figure 1. MMP2 expression in the stroma of an HER2-positive tumor; magnification, (A) $\times 40$ and (B) $\times 400$. (C) Absence of stromal MMP2 positivity in the stroma of normal breast tissue; magnification, x200. MMP2, matrix metalloproteinase 2; HER2, human epidermal growth factor receptor 2 .

cell proliferation, angiogenesis and metastasis $(3,4,14)$. Certain breast CAFs, which are characterized by SMA expression and are referred to as PMYs, appear to play an important role in metastasis, including lymph node metastasis $(3,4)$. Therefore, similar to the epithelial counterpart, it was hypothesized that the tumor's aggressiveness may be affected by the stromal composition, as well as the stroma's own biological properties ('stromal signature') $(15,16)$. In the present study, we demonstrated that the stromal expression of MMP2, which is known to promote cancer invasion and metastasis by degrading various components of the extracellular matrix, varies according to the different tumor subtypes. In particular, in HER2-positive (luminal-HER2 and HER2-enriched) and triple-negative tumors, stromal expression of MMP2 was more frequently detected compared with the luminal subtypes (Table II). Of note, it was recently indicated that, on multivariate analysis, luminal-HER2, HER2-enriched and triple-negative tumors are associated with a higher rate of distant metastasis, including brain, liver and lung metastases $(13,17)$. Therefore, the metastatic potential may be determined by the intrinsic properties of the epithelial component of the different breast tumor subtypes, as well as by the stromal properties of the microenvironment, as in the present case, by expressing different MMP2 levels, which have been implicated in the degradation of extracellular matrix and the enhancement of tumor cell motility $(7,18-20)$. In conclusion, different stromal properties, such as MMP2 expression, may predispose the different histological breast tumor subtypes to different metastatic outcomes. Further studies are
Table II. MMP2 stromal expression according to the different clinicopathological characteristics.

\begin{tabular}{|c|c|c|c|}
\hline \multirow[b]{2}{*}{ Characteristics } & \multicolumn{2}{|c|}{ MMP2 expression, no. } & \multirow[b]{2}{*}{ P-value } \\
\hline & Positive & Negative & \\
\hline Age (years) & & & 0.95 \\
\hline$\leq 50$ & 7 & 39 & \\
\hline$>50$ & 17 & 92 & \\
\hline Tumor size (mm) & & & 0.02 \\
\hline$\leq 20$ & 19 & 71 & \\
\hline$>20$ & 5 & 60 & \\
\hline Lymph node status & & & 0.11 \\
\hline Negative & 17 & 70 & \\
\hline Positive & 7 & 61 & \\
\hline Histological grade & & & 0.17 \\
\hline 1 & 2 & 25 & \\
\hline 2 & 8 & 55 & \\
\hline 3 & 14 & 51 & \\
\hline ER status & & & 0.075 \\
\hline Negative & 6 & 15 & \\
\hline Positive & 18 & 116 & \\
\hline PR status & & & 0.09 \\
\hline Negative & 9 & 28 & \\
\hline Positive & 15 & 103 & \\
\hline HER2 status & & & 0.002 \\
\hline Negative & 14 & 112 & \\
\hline Positive & 10 & 19 & \\
\hline Ki-67 & & & 0.45 \\
\hline$<15 \%$ & 4 & 31 & \\
\hline$\geq 15 \%$ & 20 & 100 & \\
\hline Molecular subtypes & & & 0.025 \\
\hline Luminal A & 2 & 32 & \\
\hline Luminal B & 11 & 75 & \\
\hline Luminal-HER2 & 7 & 12 & \\
\hline HER2-enriched & 3 & 7 & \\
\hline Triple-negative & 1 & 5 & \\
\hline
\end{tabular}

MMP2, matrix metalloproteinase 2; ER, estrogen receptor; PR, progesterone receptor; HER2, human epidermal growth factor receptor.

in progress, with the aim to accurately characterize stromal properties based on breast cancer subtype classification.

\section{References}

1. Luo H, Tu G, Liu Z and Liu M: Cancer-associated fibroblasts: A multifaceted driver of breast cancer progression. Cancer Lett 361: 155-163, 2015.

2. Han Y, Zhang Y, Jia T and Sun Y: Molecular mechanism underlying the tumor-promoting functions of carcinoma-associated fibroblasts. Tumour Biol 36: 1385-1394, 2015.

3. Catteau X, Simon P and Noël JC: Myofibroblastic stromal reaction and lymph node status in invasive breast carcinoma: Possible role of the TGF- $\beta 1 /$ TGF- $\beta R 1$ pathway. BMC Cancer 14: 499, 2014. 
4. Catteau X, Simon P and Noël JC: Myofibroblastic reaction is a common event in metastatic disease of breast carcinoma: A descriptive study. Diagn Pathol 9: 196, 2014.

5. Kohlhapp FJ, Mitra AK, Lengyel E and Peter ME: MicroRNAs as mediators and communicators between cancer cells and the tumor microenvironment. Oncogene April 13, 2015 (Epub ahead of print).

6. Hassona Y, Cirillo N, Heesom K, Parkinson EK and Prime SS: Senescent cancer-associated fibroblasts secrete active MMP-2 that promotes keratinocyte dis-cohesion and invasion. Br J Cancer 111: 1230-1237, 2014.

7. Jezierska A and Motyl T: Matrix metalloproteinase-2 involvement in breast cancer progression: A mini-review. Med Sci Monit 15: RA32-RA40, 2009.

8. LakhaniSR,Ellis IO,Schnitt SJ, Tan PH and van de Vijver MJ (eds) Invasive breast carcinoma: Introduction and general features. In WHO Classification of Tumours. Vol 4. 4th edition. IARC Press Lyon, pp19-pp22, 2012.

9. Hammond ME, Hayes DF, Dowsett M, Allred DC, Hagerty KL, Badve S, Fitzgibbons PL, Francis G, Goldstein NS, Hayes M, et al: American Society of Clinical Oncology/College of American Pathologists guideline recommendations for immunohistochemical testing of estrogen and progesterone receptors in breast cancer. J Clin Oncol 28: 2784-2795, 2010

10. Wolff AC, Hammond ME, Hicks DG, Dowsett $M$, McShane LM, Allison KH, Allred DC, Bartlett JM, Bilous M, Fitzgibbons P, et al: Recommendations for human epidermal growth factor receptor 2 testing in breast cancer: American Society of Clinical Oncology/College of American Pathologists clinical practice guideline update. J Clin Oncol 31: 3997-4013, 2013.

11. Preat F, Simon P and Noel JC: Differences in breast carcinoma immunohistochemical subtypes between immigrant Arab and European women. Diagn Pathol 9: 26, 2014.
12. Sihto H, Lundin J, Lundin M, Lehtimäki T, Ristimäki A, Holli K, Sailas L, Kataja V, Turpeenniemi-Hujanen T, Isola J, et al: Breast cancer biological subtypes and protein expression predict for the preferential distant metastasis sites: A nationwide cohort study. Breast Cancer Res 13: R87, 2011.

13. Kennecke H, Yerushalmi R, Woods R, Cheang MC, Voduc D, Speers CH, Nielsen TO and Gelmon K: Metastatic behavior of breast cancer subtypes. J Clin Oncol 28: 3271-3277, 2010.

14. De Wever O, Demetter P, Mareel M and Bracke M: Stromal myofibroblasts are drivers of invasive cancer growth. Int J Cancer 123: 2229-2238, 2008.

15. Finak G, Bertos N, Pepin F, Sadekova S, Souleimanova M, Zhao H, Chen H, Omeroglu G, Hallett M and Park M: Stromal gene expression predicts clinical outcome in breast cancer. Nat Med 14: 518-527, 2008.

16. Farmer P, Bonnefoi H, Anderle P, Cameron D, Wirapati P, Becette V, André S, Piccart M, Campone M, Brain E, et al: A stroma-related gene signature predicts resistance to neoadjuvant chemotherapy in breast cancer. Nat Med 15: 68-74, 2009.

17. Gupta GP and Massagué J: Cancer metastasis: Building a framework. Cell 127: 679-695, 2006.

18. Duffy MJ, Maguire TM, Hill A, McDermott E and O'Higgins N: Metalloproteinases: Role in breast carcinogenesis, invasion and metastasis. Breast Cancer Res 2: 252-257, 2000.

19. Jones JL, Glynn P and Walker RA: Expression of MMP-2 and MMP-9, their inhibitors and the activator MT1-MMP in primary breast carcinomas. J Pathol 189: 161-168, 1999.

20. Thompson EW, Yu M, Bueno J, Jin L, Maiti SN, Palao-Marco FL, Pulyaeva H, Tamborlane JW, Tirgari R and Wapnir I: Collagen induced MMP-2 activation in human breast cancer. Breast Cancer Res Treat 31: 357-370, 1994. 